\title{
Synthesis of $\mathrm{Mo}_{4} \mathrm{VAlC}_{4}$ MAX Phase and Two- Dimensional $\mathrm{Mo}_{4} \mathrm{VC}_{4} \mathrm{MXene}$ with 5 Atomic Layers of Transition Metals
}

\author{
Grayson Deysher $^{a}$, Christopher Eugene Shuck ${ }^{a}$, Kanit Hantanasirisakul $^{a}$, Nathan C. Frey, $^{b}$ \\ Alexandre C. Foucher ${ }^{b}$, Kathleen Maleski ${ }^{a}$, Asia Sarycheva ${ }^{a}$, Vivek B. Shenoy ${ }^{b}$, Eric A. Stach $^{b}$, \\ Babak Anasori ${ }^{a, c *}$, Yury Gogotsi ${ }^{a *}$ \\ ${ }^{a}$ Department of Materials Science and Engineering, and A.J. Drexel Nanomaterials Institute, Drexel \\ University, Philadelphia, Pennsylvania 19104, United States \\ ${ }^{b}$ Department of Materials Science and Engineering, University of Pennsylvania, Philadelphia, \\ Pennsylvania 19104, United States \\ ${ }^{c}$ Department of Mechanical and Energy Engineering, and Integrated Nanosystems Development Institute, \\ Purdue School of Engineering and Technology, Indiana University-Purdue University Indianapolis, \\ Indianapolis, Indiana 46202, United States
}

Yury Gogotsi: gogotsi@drexel.edu B Babak Anasori: $\underline{\text { banasori@iupui.edu }}$

\section{Supporting Information}

\section{$\mathrm{Mo}_{4} \mathrm{VAlC}_{4} \mathrm{MAX}$ PHASE SYNTHESIS AND WASHING}

To explore the entire $(\mathrm{MoV})_{5} \mathrm{AlC}_{4}$ system, we mixed samples covering the whole range from $0-100 \%$ Mo (Supporting Figure 1A). It was found that only the 4:1 Mo:V ratio sample resulted in the desired $\mathrm{M}_{5} \mathrm{AX}_{4}$ phase. The other ratios either resulted in other $\mathrm{M}_{n+1} \mathrm{AX}_{n}(\mathrm{MAX})$ phases or carbides (Supporting Figure 1B). To more closely examine the impact of Mo:V ratio, additional samples were mixed with $\mathrm{Mo}_{x}: \mathrm{V}_{5-x}$ ratios of $\mathrm{x}=3.50,3.75,4.00,4.25$, and 4.50, of which those where $\mathrm{x}=3.75,4.00$, and 4.25 resulted in $(\mathrm{MoV})_{5} \mathrm{AlC}_{4}$ although the 3.75:1.25 sample contained $(\mathrm{MoV})_{4} \mathrm{AlC}_{3}$ as an impurity. Those where $\mathrm{x}=3.50$ and 4.50 resulted in $\mathrm{M}_{4} \mathrm{AX}_{3} \mathrm{MAX}$ phase and bulk Mo/V carbides respectively. Supporting Figure 2 shows how the $c$ - and $a$-LPs are affected by the Mo: $\mathrm{V}$ ratio. The (002), (004), and (006) peaks define expansion or compaction in the MAX phase unit cell and, as shown by Supporting Figure $2 \mathrm{~A}-\mathrm{C}$, there is no significant shift in their peak positions. This seems to indicate that if there are varying amounts of Mo and $\mathrm{V}$ in the structure, it will not significantly expand or contract in the $c$ direction. Supporting Figure 2D shows the (110) peak, which indicates the $a$-LP. There is indeed a noticeable shift as the Mo:V ratio increases. From a Mo:V ratio of 3.75:1.25 to 4.25:0.75 there is an expansion in the $a$-LP of about $0.27 \%(0.8 \mathrm{pm})$. The expected percentage expansion for this increase in Mo: $\mathrm{V}$ ratio based on the ratio of $\mathrm{Mo}: \mathrm{V}$ atomic radii, which is $1.03 \%$. It is hypothesized that due to the presence of $(\mathrm{MoV})_{4} \mathrm{AlC}_{3}$ with an unknown $\mathrm{Mo}: \mathrm{V}$ ratio, and slight errors in the initial weighing of the elemental 
powders, the amount of $\mathrm{Mo}: \mathrm{V}$ ratio in the $(\mathrm{MoV})_{5} \mathrm{AlC}_{4}$ structure will be slightly different, which would lead to a sample that experienced more or less expansion than expected. This indicates that the ratio can be varied, which implies that the structure is a solid solution on the M sites.

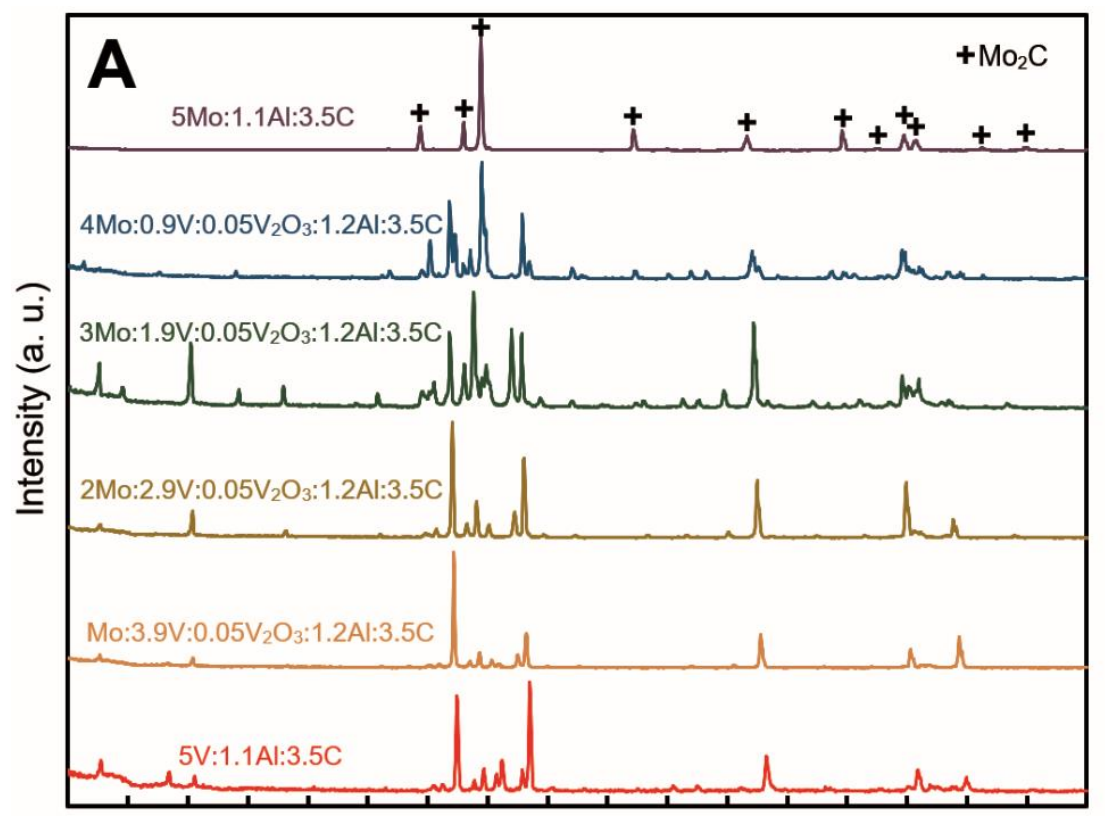

$\begin{array}{llllllllllllllllll}5 & 10 & 15 & 20 & 25 & 30 & 35 & 40 & 45 & 50 & 55 & 60 & 65 & 70 & 75 & 80 & 85 & 905\end{array}$ $2 \theta\left({ }^{\circ}\right)$

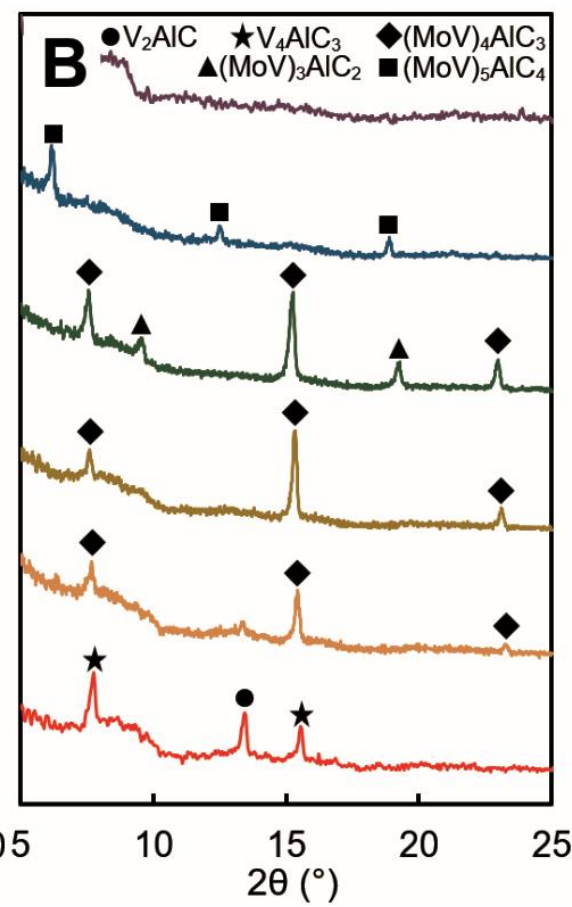

$2 \theta\left({ }^{\circ}\right)$

Supporting Figure 1. XRD patterns of MAX phase samples. A) Full XRD patterns for the materials resulting from mixing various compositions of the $\mathrm{Mo}_{x} \mathrm{~V}_{5-x} \mathrm{AlC}_{4}$ system where $\mathrm{x}$ ranges from 0-5 (0-100\% Mo). Only $M_{0} V_{V A I C}$ produces an $M_{5} A X_{4}$ phase. $B$ ) Zoom-in view of the same XRD patterns showing the non- $M_{5} A X_{4}$ $\mathrm{MAX}$ phases that resulted from the various ratios of Mo: $\mathrm{V}$. 

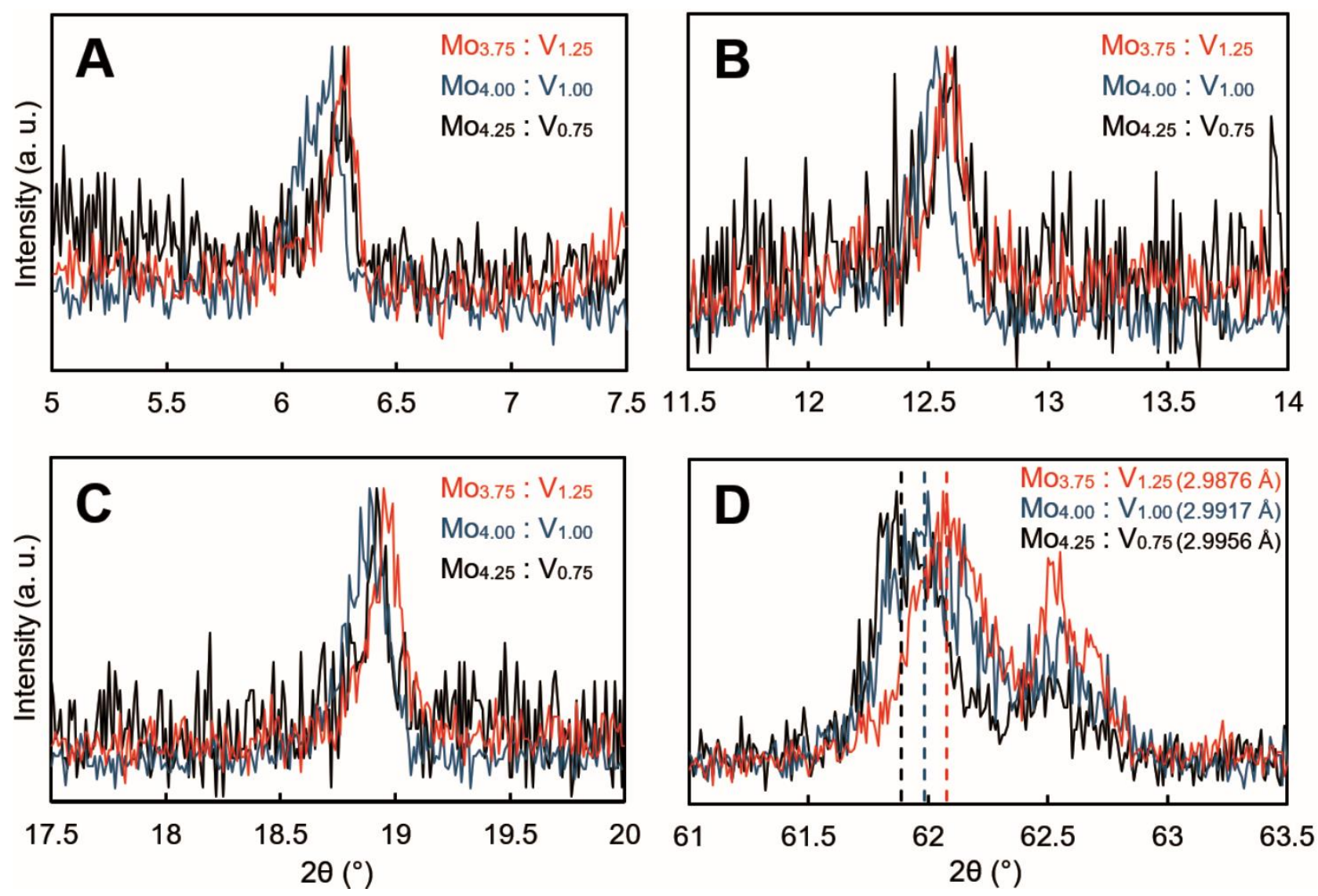

Supporting Figure 2. XRD patterns of three samples made with Mo:V ratios of 3.75:1.25, 4.00:1.00, and 4.25:0.75. Zoom-in views are provided for the A) (002) peak, B) (004) peak, C) (006) peak, and D) (110) peak also showing the $a$-LP for each sample.

While the MAX phase sample powder contained only one type of MAX phase, there were additional impurities present. To remove some of these, namely $\mathrm{Al}_{4} \mathrm{C}_{3}$, the powder was washed with $12 \mathrm{M} \mathrm{HCl}$. XRD confirms the removal of $\mathrm{Al}_{4} \mathrm{C}_{3}$ after washing (Supporting Figure 3). 


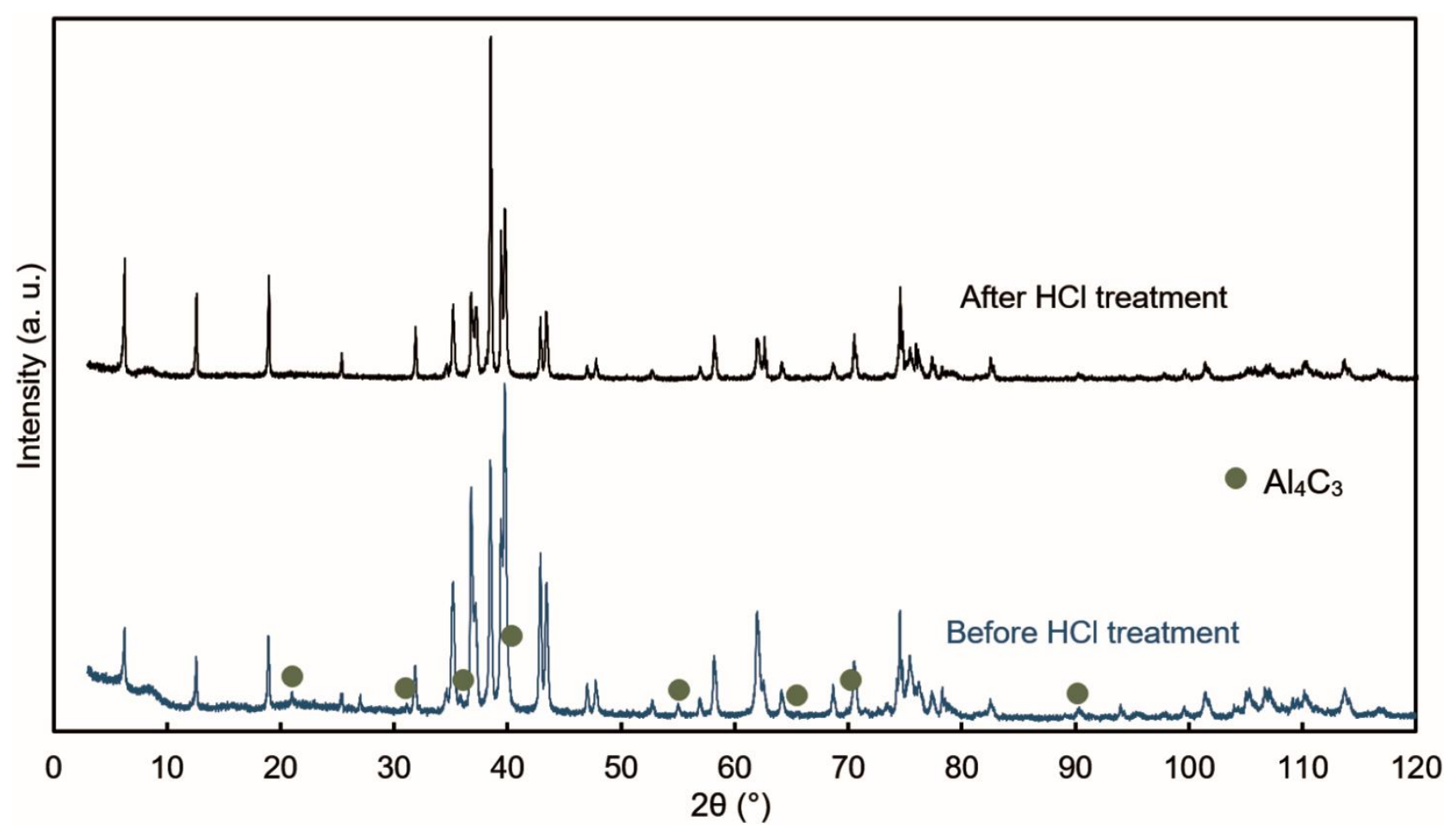

Supporting Figure 3. XRD patterns of the $\mathrm{Mo}_{4} \mathrm{VAIC}_{4}$ powder as produced and after $\mathrm{HCl}$ treatment. The $\mathrm{Al}_{4} \mathrm{C}_{3}$ peaks are no longer present after washing indicating that this carbide was successfully removed.

Interestingly, $\mathrm{V}_{2} \mathrm{O}_{3}$ is required in the initial mix to form the $\mathrm{Mo}_{4} \mathrm{VAlC}_{4}$ phase. As for the $\mathrm{V}$ source, we used $\mathrm{V}: \mathrm{V}_{2} \mathrm{O}_{3}$ 0.9:0.05 instead of pure $\mathrm{V}$ in the starting powder mixture for the MAX synthesis. Without the addition of $\mathrm{V}_{2} \mathrm{O}_{3}$ the resulting material contains $\mathrm{Mo}_{2} \mathrm{C}$ and $\mathrm{VC}$ (Supporting Figure 4). It is not clear why $\mathrm{V}_{2} \mathrm{O}_{3}$ is needed, but the oxygen might act as a catalyst for this reaction, substitute for carbon on the lattice forming oxicarbide, or potentially the extra heat produced during the thermal reduction of $\mathrm{V}_{2} \mathrm{O}_{3}$ by $\mathrm{Al}$ pushes the sample into the $(\mathrm{MoV})_{5} \mathrm{AlC}_{4}$ region of this quaternary phase diagram. 


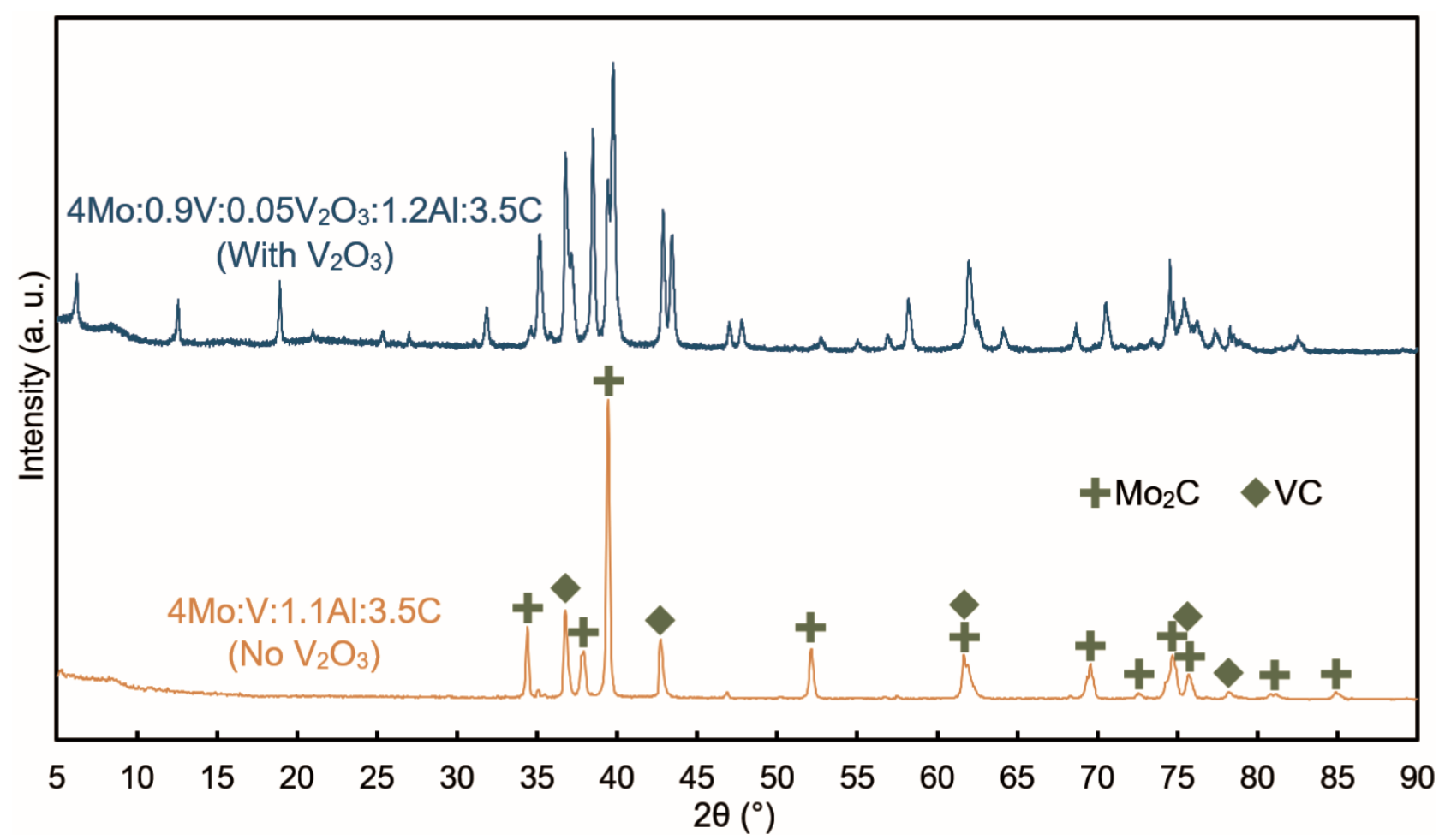

Supporting Figure 4. XRD patterns of $\mathrm{Mo}_{4} \mathrm{VAIC}_{4}$ powder as produced without (orange) and with (blue) $\mathrm{V}_{2} \mathrm{O}_{3}$.

The mixture of elemental and oxide powders (molybdenum (99.9\% Alfa Aesar, -250 mesh), vanadium (99.5\% Alfa Aesar, -325 mesh), vanadium (III) oxide (98\% Sigma Aldrich), aluminum (99.5\% Alfa Aesar, -325 mesh), and graphite (99\% Alfa Aesar, -325 mesh) was divided into $7 \mathrm{~g}$ quantities that were each poured into $10 \mathrm{~mL}$ alumina crucibles. To compact the powder in the crucibles, they were each tapped gently on the counter 80 times, rotating the crucible 90 degrees after every 20 taps to ensure a level top for even heating.

To wash the MAX after the $\mathrm{HCl}$ treatment, $50 \mathrm{~mL}$ of $\mathrm{HCl} / \mathrm{MAX}$ phase mixture was poured into a $50-\mathrm{mL}$ centrifuge tube and centrifuged at $3500 \mathrm{rpm}$ ( $2550 \mathrm{rcf})$ for $2 \mathrm{~min}$. Afterwards, the MAX phase particles had settled to the bottom of the centrifuge tube as sediment and the supernatant was transparent. There were also many particles of PTFE floating in the solution. This is due to the high hardness of the MAX phase sample powder which wears away the PTFE stir bars. These particles should be skimmed off to avoid contamination of the sample. This supernatant was decanted off into an appropriate $\mathrm{HCl}$ waste bottle. Fresh DI water was added to the tube and, after securing the cap, the tube was hand-shaken to re-disperse the MAX phase sediment. The same centrifugation and decantation procedure was repeated 4 additional times to neutralize the MAX phase mixture.

\section{$\mathrm{Mo}_{4} \mathrm{VC}_{4}$ MULTILAYER MXene WASHING}

The $40 \mathrm{~mL}$ of HF/MXene solution was poured into a $250 \mathrm{~mL}$ centrifuge tube. Additional DI water was added to fill the tube. The tube was centrifuged at $3500 \mathrm{rpm}$ (2550 rcf) for $3 \mathrm{~min}$. Afterwards, all the multilayer MXene had settled to the bottom of the tube and the supernatant was 
transparent with a slight tint of green due to dissolved vanadium oxide (Supporting Figure 5A). Again, PTFE particles are present and float to the top. This supernatant was decanted off into an appropriate HF waste bottle. Fresh DI water was added to the tube and, after securing the cap, the tube was hand-shaken to re-disperse the multilayer MXene sediment. The same centrifugation and decantation procedure was repeated and the resulting supernatant was transparent and colorless (Supporting Figure 5B). The washing procedure was repeated 3 additional times with the centrifugation step lasting $15 \mathrm{~min}$ to neutralize the multilayer MXene. Each subsequent supernatant was also colorless.
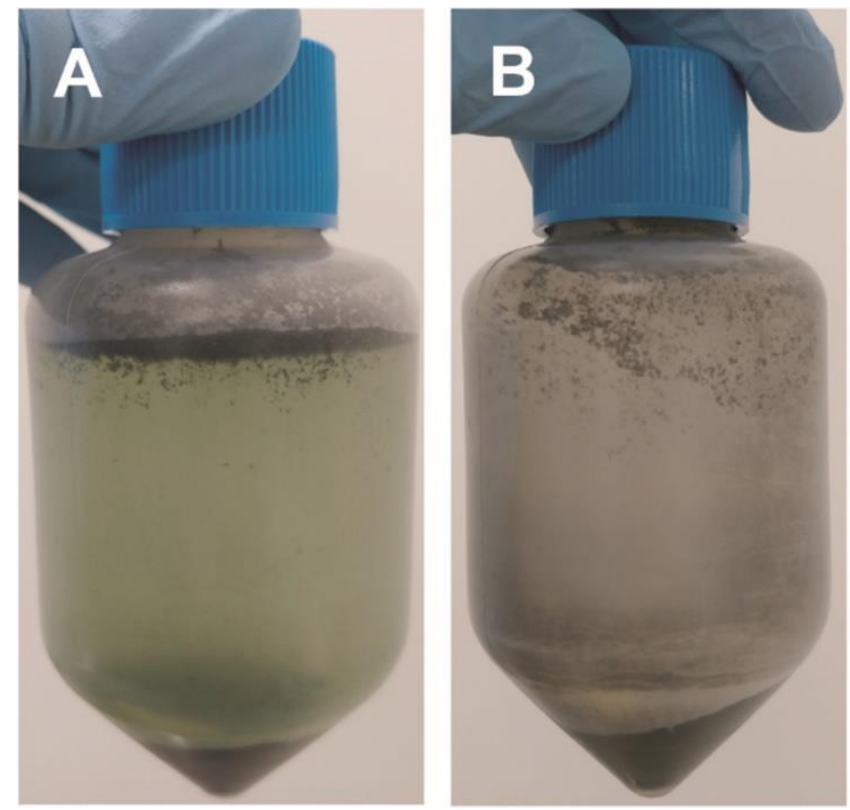

Supporting Figure 5. Analysis of supernatant. A) Green-tinted supernatant after the first wash cycle. B) Colorless supernatant after each subsequent cycle. The particles at the top are PTFE from the stir bar and are removed during washing steps.

\section{$\mathrm{Mo}_{4} \mathrm{VC}_{4}$ MXene DELAMINATION WASHING}

A more aggressive centrifugation cycle was needed to wash the delaminated MXene. Washing can still be done at $3500 \mathrm{rpm}$ ( $2550 \mathrm{rcf}$ ) however it takes much longer to settle the MXene flakes. Typically, at $3500 \mathrm{rpm}$ ( $2550 \mathrm{rcf}$ ), each washing cycle is $>1 \mathrm{~h}$. Since the solution heats up during this long centrifugation, in between washes, the solution should be cooled back down in a refrigerator for $10 \mathrm{~min}$ before the next centrifugation to avoid oxidation and degradation of the flakes. Ideally, centrifugation can be done at $8000 \mathrm{rpm}(8230 \mathrm{rcf})$ for $30 \mathrm{~min}$ cycles. For delaminating $0.25 \mathrm{~g}$ of multilayer MXene, 5 washes are needed to achieve a neutral $\mathrm{pH}$.

\section{$\mathrm{Mo}_{4} \mathrm{VC}_{4}$ MXene DELAMINATION OPTIMIZATION}

As a part of optimizing the delamination procedure, various concentrations of TMAOH were used to delaminate samples. TMAOH can lead to degradation of the MXene flakes so ideally, the lowest TMAOH concentration possible that still produces a reasonable yield $(>1 \mathrm{mg} / \mathrm{mL})$ should be used. After washing each sample to neutral $\mathrm{pH}$, the sediment was bath sonicated for $1 \mathrm{~h}$ 
with Argon bubbling. Each sample, containing $30 \mathrm{~mL}$ of solution, was centrifuged at $3500 \mathrm{rpm}$ ( $2550 \mathrm{rcf}$ ) for $1 \mathrm{~h}$ to obtain a dark supernatant. After centrifugation, the supernatants were carefully removed with a $3 \mathrm{~mL}$ pipette and transferred into a vacuum-assisted filtration setup. The resulting films were dried in a vacuum desiccator for $12 \mathrm{~h}$ at $25^{\circ} \mathrm{C}$ and then weighed with a Mettler Toledo UMX2 Ultra-microbalance to determine the mass yield of each TMAOH concentration. After testing 6 different concentrations ranging from 1-25 wt.\%, all samples had roughly the same yield (Supporting Figure 6). It is worth noting that the mass yield of the synthesis of multilayer MXene is quite a high percentage of the initial weight of the MAX phase powder as shown by the lack of MAX phase peaks in the XRD pattern (Figure 2). The mass yield for the MXene delamination to obtain pure single flakes is $\sim 2.5 \%$ of the initial weight of the MAX phase powder. This yield could likely be increased though, with further optimization of the synthesis method including etching duration and particle size.

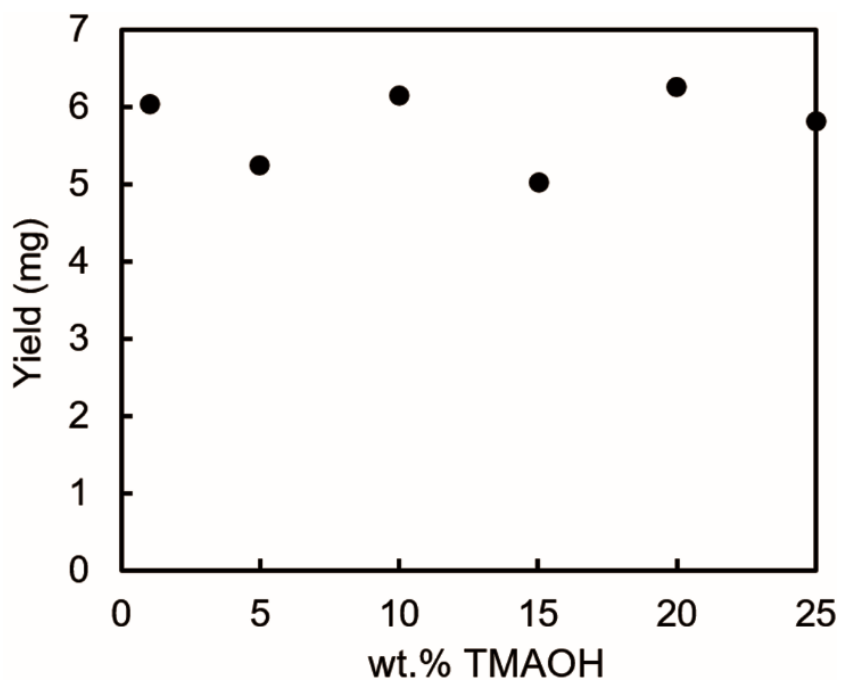

Supporting Figure 6. Mass yield of the delamination procedure as a function of TMAOH concentration. For the concentrations tested, there is minimal variation in weight of the resulting MXene film.

In addition to the yield of the delamination method, the quality of the resulting flakes is also important. Some of the colloid of each of these samples was drop-cast onto porous alumina substrates and SEM was used to determine the apparent quality of the flakes. These samples are shown in Supporting Figure 7. The samples delaminated with 15, 20, and 25 wt.\% TMAOH resulted in the formation of flakes $\sim 750 \mathrm{~nm}$ in lateral size, however, holes appeared. The sample delaminated with 1 wt.\% TMAOH had no holes but the flake size was smaller $(\sim 640 \mathrm{~nm})$. Additionally, $5 \mathrm{wt} . \%$ TMAOH results in both smaller flakes $(\sim 480 \mathrm{~nm})$ and some holes. Therefore, $10 \mathrm{wt} . \%$ TMAOH was chosen as the optimal concentration to produce larger $\mathrm{Mo}_{4} \mathrm{VC}_{4}$ flakes $(\sim 700$ $\mathrm{nm}$ ) with the least degradation. 

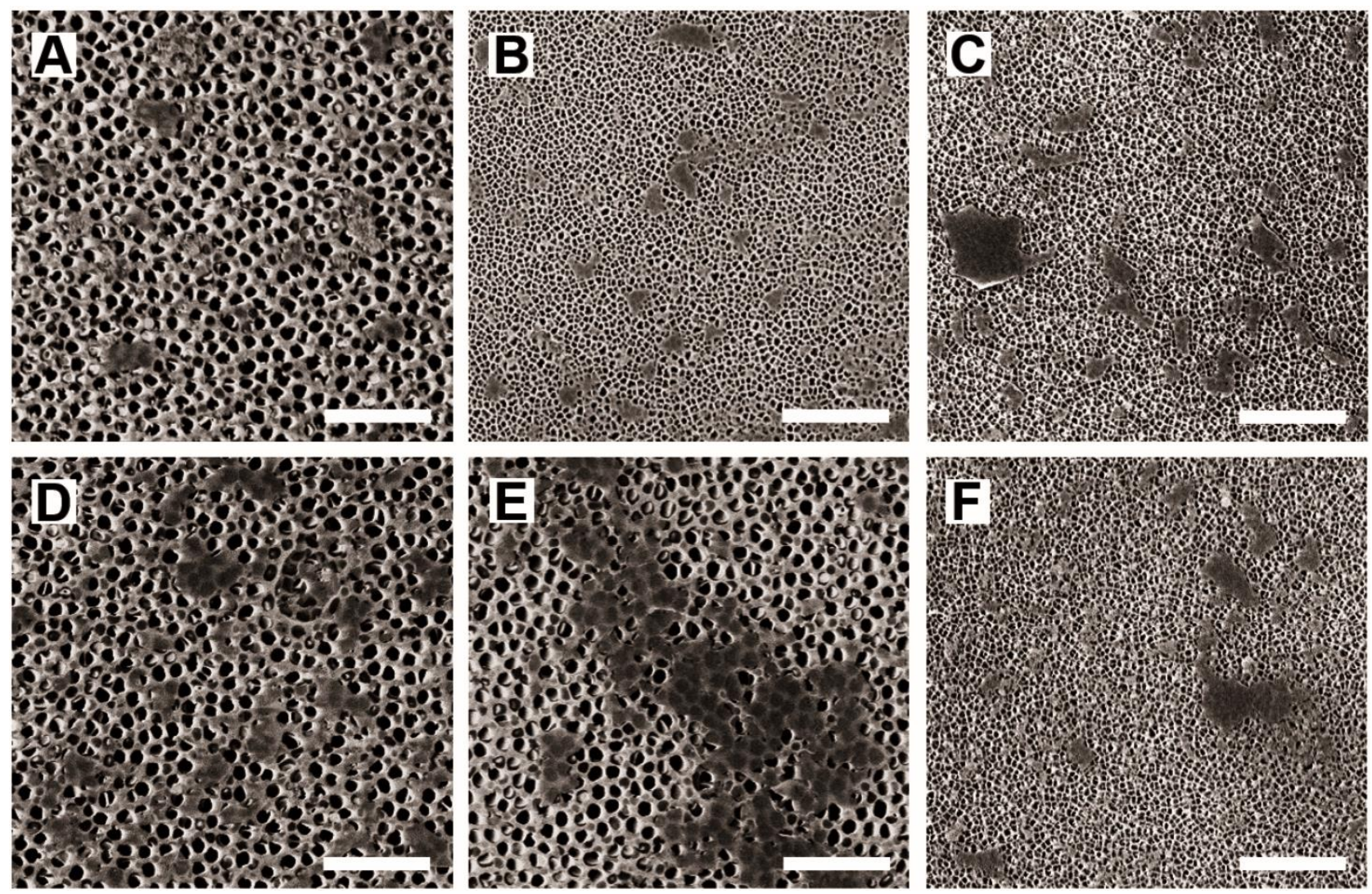

Supporting Figure 7. SEM micrographs of the drop-cast $\mathrm{Mo}_{4} \mathrm{VC}_{4}$ single flakes produced with various concentrations of TMAOH. A) 1 wt.\%. B) 5 wt.\%. C) 10 wt.\%. D) 15 wt.\%. E) 20 wt.\%. F) 25 wt.\%. Holes are visible in the flakes produced with 15, 20, and $25 \mathrm{wt} . \% \mathrm{TMAOH}$. Each scale bar is $2 \mu \mathrm{m}$.

\section{MICROSCOPY}

Supporting Figure 8A shows a dark field STEM micrograph of $\mathrm{Mo}_{4} \mathrm{VAlC}_{4}$. Supporting Figure $8 \mathrm{~B}-\mathrm{C}$ shows TEM micrographs of a drop cast single flake of $\mathrm{Mo}_{4} \mathrm{VC}_{4}$. One of the flakes edges is oriented parallel to the beam allowing for observation of the 5 atomic layers of $\mathrm{Mo} / \mathrm{V}$. The micrograph quality is limited due to the sensitivity of the single flake to the electron beam. A SEM micrograph of the cross-section of a film produced by filtering the colloid produced by delamination is provided in Supporting Figure 8D. The flakes arrange themselves flat along their basal planes and stack on top of each other. 

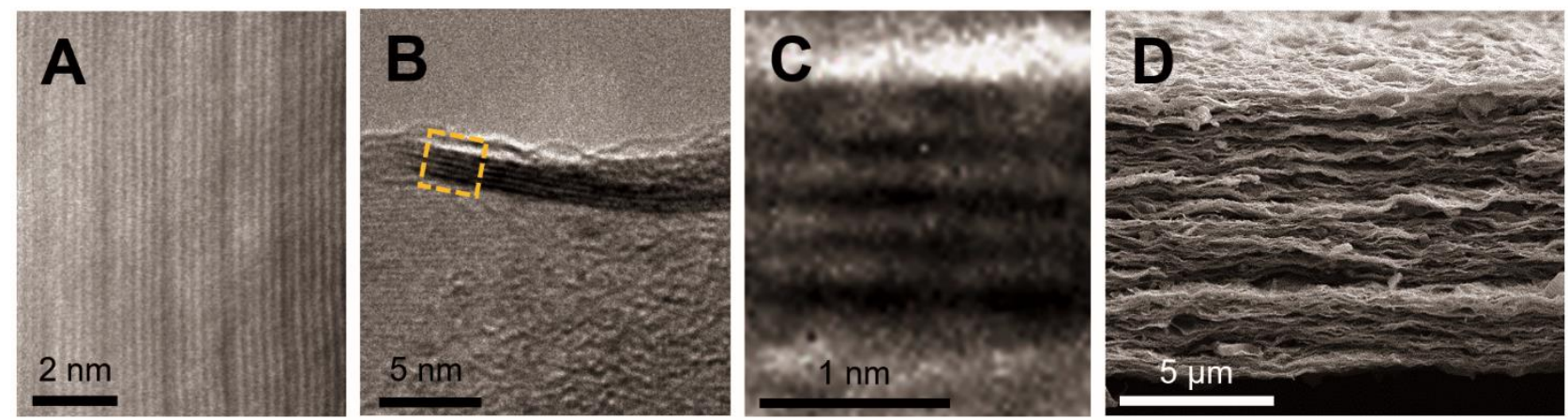

Supporting Figure 8. TEM analysis of MXene. A) STEM dark field micrograph of $\mathrm{Mo}_{4} \mathrm{VAIC}_{4} \mathrm{MAX}$ phase. B) TEM micrograph of a $\mathrm{Mo}_{4} \mathrm{VC}_{4}$ single flake drop cast onto a TEM grid. C) Zoom-in view of the micrograph in $B$ with a slight rotation. The region shown in $C$ is indicated by the dashed rectangle in $B$. D) SEM micrograph of a cross-section of a film produced be filtering a colloid of these delaminated flakes.

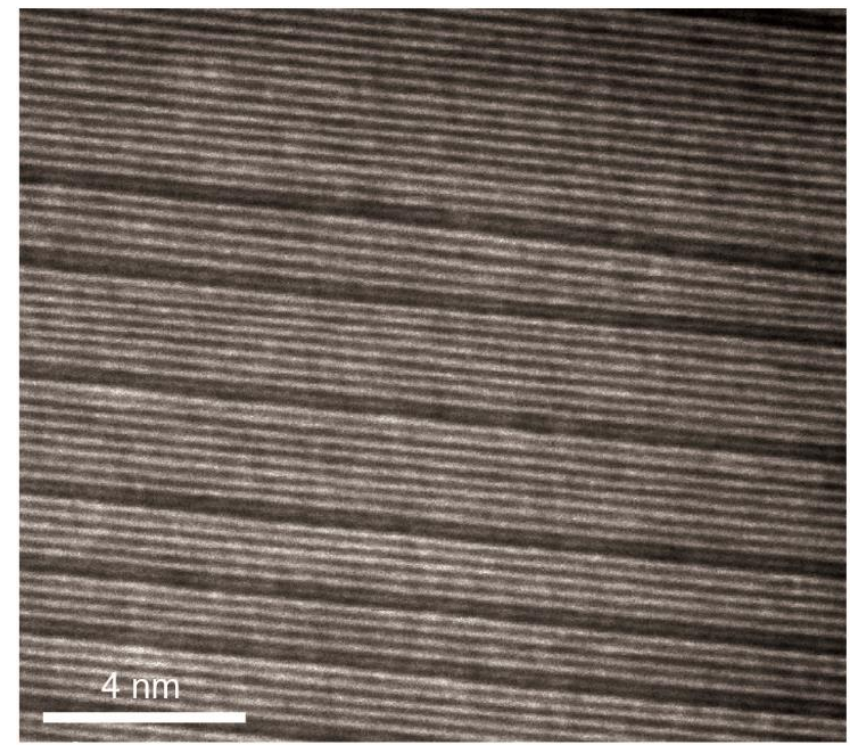

Supporting Figure 9. TEM analysis of $\mathrm{Mo}_{4} \mathrm{VAIC}$ MAX phase. STEM dark field micrograph of $\mathrm{Mo}_{4} \mathrm{VAIC}_{4} \mathrm{MAX}$ phase in a location showing an irregular structure containing thicker slabs of Mo/V layers. This is due to a lack of Al layers. This is consistent with the EDS results that show a lower than stoichiometric amount of Al.

Supporting Figure 10 shows a high-resolution EDS line scan of $\mathrm{Mo}_{4} \mathrm{VAlC}_{4} \mathrm{MAX}$ phase. EDS indicates that the Al layers are ordered with the Mo/V slabs, in agreement with the varying intensity between the expected $\mathrm{Al}$ and Mo/V layers in the HRSTEM micrographs. EDS also indicates a lack of distinct order within the 5-layer Mo/V slabs thus confirming that the structure contains a solid solution on the M sites. 

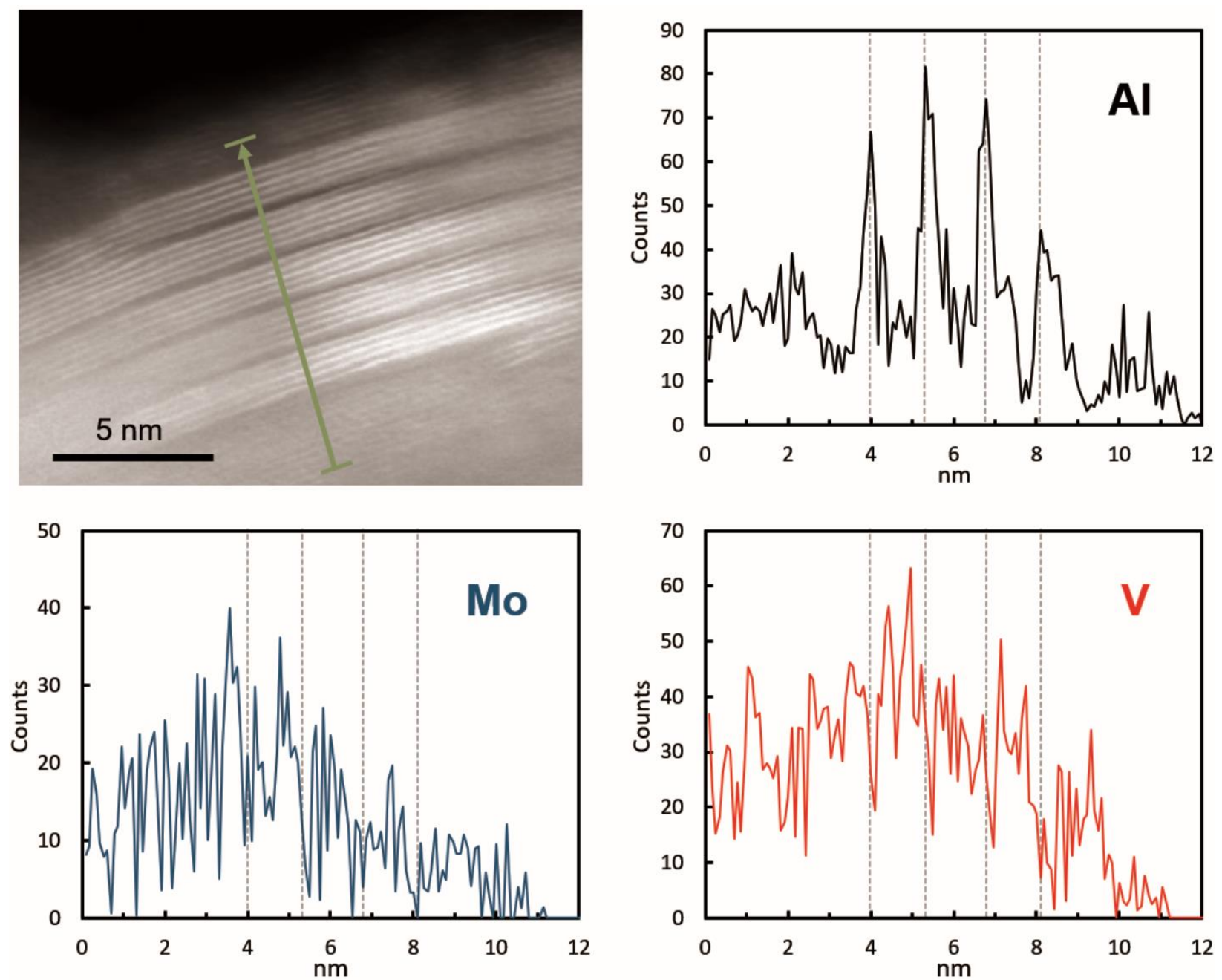

Supporting Figure 10. High-resolution EDS analysis of $\mathrm{Mo}_{4} \mathrm{VAIC}_{4} \mathrm{MAX}$ phase. High-resolution EDS line scan of $\mathrm{Mo}_{4} \mathrm{VAlC}_{4}$ showing distinct and repetitive Al peaks. There is no distinguishable pattern of Mo and $\checkmark$ within the Mo/V layers. 


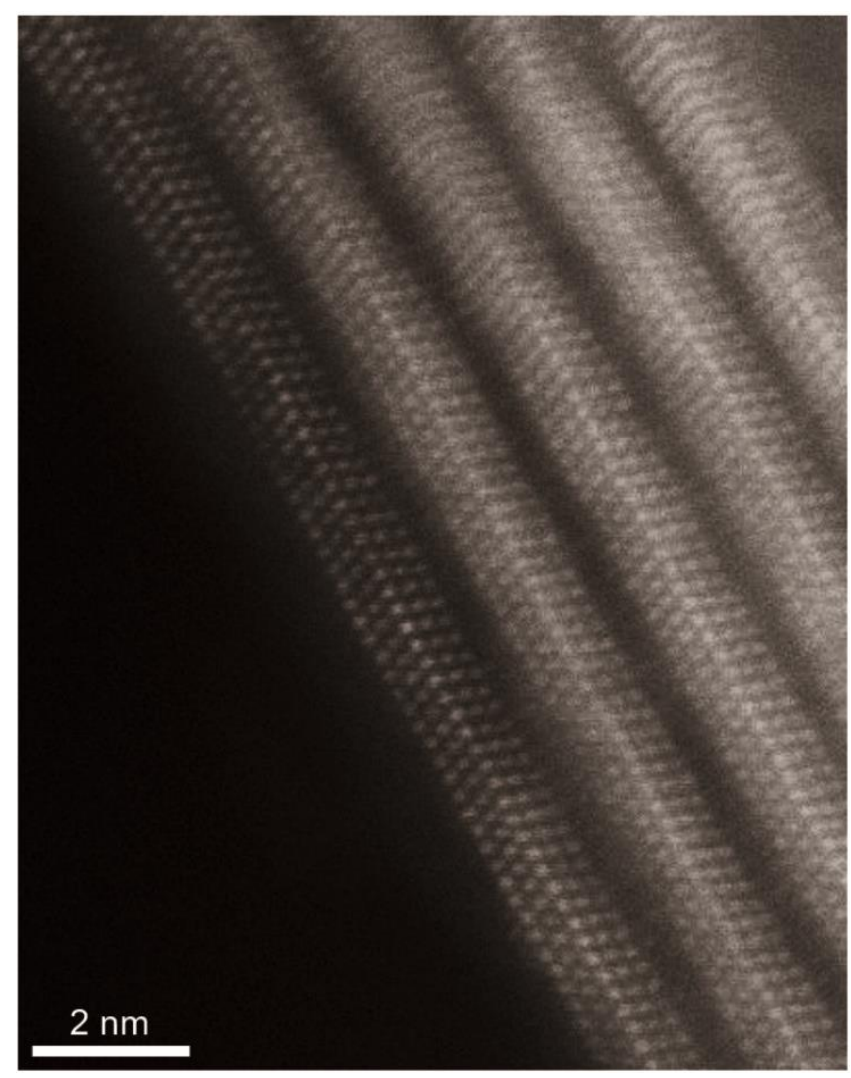

Supporting Figure 11. TEM analysis of $\mathrm{Mo}_{4} \mathrm{VC}_{4} \mathrm{MXene}$. STEM dark field micrograph of $\mathrm{Mo}_{4} \mathrm{VC}_{4}$ multilayer MXene showing slightly brighter central layers within the 5-layer structure indicating that Mo preferentially occupies the central layers in a higher Mo:V ratio than the outer 4 layers. This was only observed in some areas of the sample.

\section{XPS RESULTS}

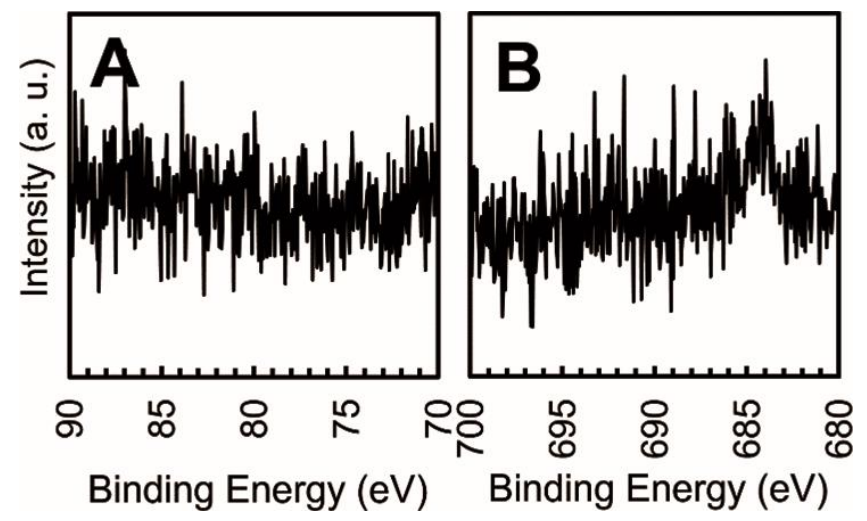

Supporting Figure 12. XPS results of $\mathrm{Mo}_{4} \mathrm{VC}_{4}$ MXene. A) Al $2 p$ region shows no presence of Al. B) $F$ 1s region shows almost no $\mathrm{F}$. 


\section{ELECTRICAL RESISTIVITY vs. TEMPERATURE}
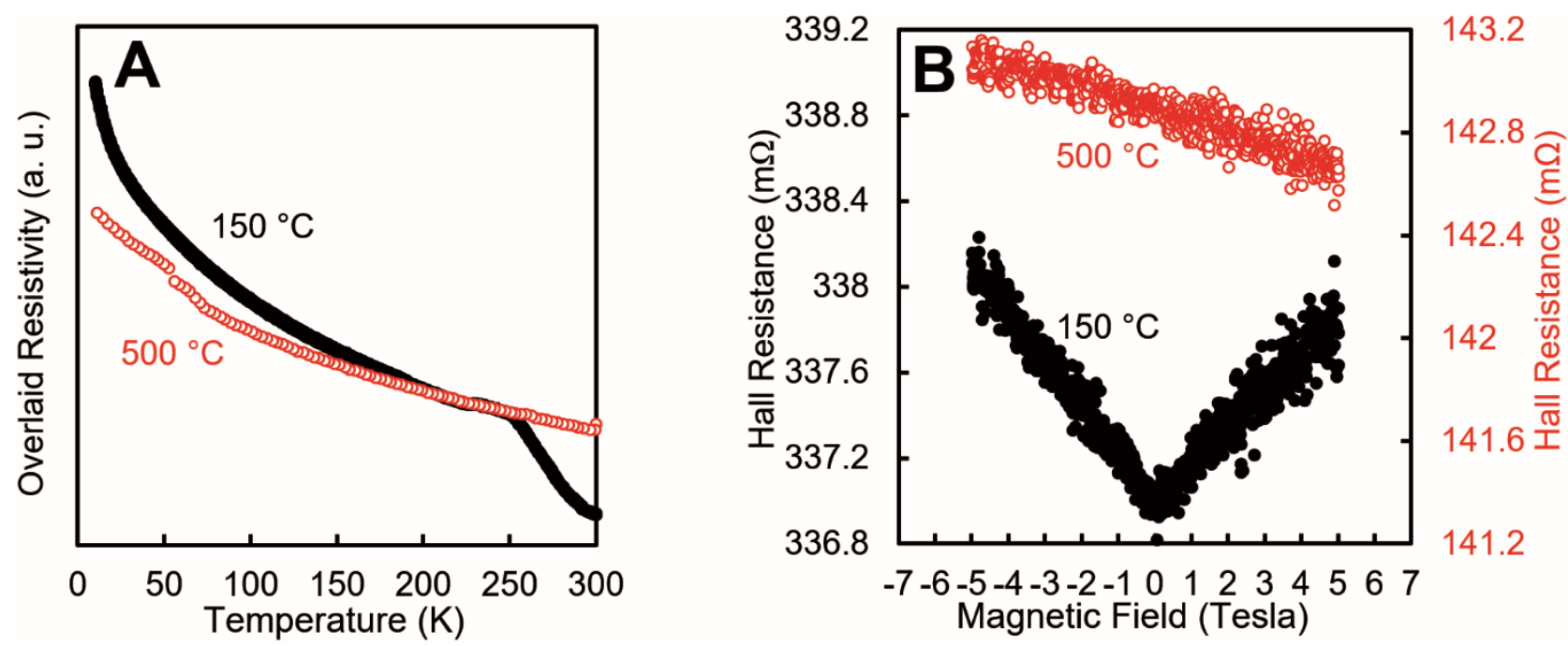

Supporting Figure 13. Low-temperature measurements. A) Overlaid electrical resistivity as a function of temperature for $\mathrm{Mo}_{4} \mathrm{VC}_{4} \mathrm{MXene}$ heat treated at $150{ }^{\circ} \mathrm{C}$ and $500{ }^{\circ} \mathrm{C}$. The slight discontinuity around $55 \mathrm{~K}$ for the sample treated at $500{ }^{\circ} \mathrm{C}$ is likely an artifact of the measurement system. B) Hall resistance of $\mathrm{Mo}_{4} \mathrm{VC}_{4} \mathrm{MXene}$ heat-treated at $150^{\circ} \mathrm{C}$ and $500^{\circ} \mathrm{C}$ measured at $10 \mathrm{~K}$.

\section{$\mathrm{Mo}_{4} \mathrm{VAlC}_{4} \mathrm{X}$-RAY DIFFRACTION DATA}

Supporting Table 1. Peak positions, $d$ spacings, and normalized intensities from the XRD pattern of the $\mathrm{Mo}_{4} \mathrm{VAIC}_{4}$ MAX phase sample powder

\begin{tabular}{|c|c|c|c|c|c|c|c|c|}
\hline $2 \theta\left({ }^{\circ}\right)$ & $\begin{array}{c}\text { d } \\
\text { Spacing } \\
(\AA)\end{array}$ & $\begin{array}{c}\text { Normalized } \\
\text { Intensity }\end{array}$ & $\begin{array}{l}\mathbf{2 \theta} \\
\left(^{\circ}\right)\end{array}$ & $\begin{array}{c}\mathbf{d} \\
\text { Spacing } \\
(\AA)\end{array}$ & $\begin{array}{c}\text { Normalized } \\
\text { Intensity }\end{array}$ & $2 \theta\left({ }^{\circ}\right)$ & $\begin{array}{c}d \\
\text { Spacing } \\
(\AA)\end{array}$ & $\begin{array}{c}\text { Normalized } \\
\text { Intensity }\end{array}$ \\
\hline 6.26 & 14.108 & 0.299 & 55.05 & 1.667 & 0.080 & 93.98 & 1.053 & 0.080 \\
\hline 12.58 & 7.031 & 0.215 & 56.88 & 1.617 & 0.098 & 94.27 & 1.051 & 0.059 \\
\hline 18.92 & 4.687 & 0.275 & 58.18 & 1.584 & 0.219 & 95.47 & 1.041 & 0.056 \\
\hline 20.97 & 4.233 & 0.113 & 61.99 & 1.496 & 0.345 & 97.99 & 1.021 & 0.056 \\
\hline 22.97 & 3.869 & 0.091 & 62.50 & 1.485 & 0.148 & 99.58 & 1.009 & 0.075 \\
\hline 25.37 & 3.508 & 0.109 & 64.11 & 1.451 & 0.119 & 101.42 & 0.995 & 0.114 \\
\hline 27.02 & 3.297 & 0.108 & 68.67 & 1.366 & 0.136 & 101.78 & 0.993 & 0.093 \\
\hline 31.85 & 2.807 & 0.190 & 70.54 & 1.334 & 0.204 & 103.95 & 0.978 & 0.079 \\
\hline 34.65 & 2.587 & 0.126 & 71.49 & 1.319 & 0.069 & 104.37 & 0.975 & 0.074 \\
\hline 35.15 & 2.551 & 0.427 & 72.66 & 1.300 & 0.062 & 104.61 & 0.973 & 0.069 \\
\hline 35.88 & 2.501 & 0.105 & 73.44 & 1.288 & 0.084 & 105.03 & 0.971 & 0.114 \\
\hline 35.89 & 2.500 & 0.101 & 74.30 & 1.276 & 0.152 & 105.35 & 0.969 & 0.120 \\
\hline 36.76 & 2.443 & 0.704 & 74.54 & 1.272 & 0.348 & 106.67 & 0.960 & 0.127 \\
\hline 37.16 & 2.418 & 0.371 & 74.75 & 1.269 & 0.207 & 107.07 & 0.958 & 0.124 \\
\hline 38.46 & 2.339 & 0.765 & 75.42 & 1.259 & 0.218 & 108.19 & 0.951 & 0.082 \\
\hline
\end{tabular}




\begin{tabular}{|c|c|c|c|c|c|c|c|c|}
\hline 39.42 & 2.284 & 0.613 & 75.94 & 1.252 & 0.130 & 109.1 & 0.946 & 0.097 \\
\hline 39.76 & 2.265 & 1.000 & 76.22 & 1.248 & 0.142 & 109.63 & 0.942 & 0.096 \\
\hline 42.88 & 2.107 & 0.513 & 77.34 & 1.233 & 0.117 & 110.16 & 0.939 & 0.121 \\
\hline 43.40 & 2.083 & 0.420 & 78.29 & 1.220 & 0.127 & 113.73 & 0.920 & 0.125 \\
\hline 46.97 & 1.933 & 0.131 & 78.52 & 1.217 & 0.097 & 114.12 & 0.918 & 0.090 \\
\hline 47.73 & 1.904 & 0.135 & 82.53 & 1.168 & 0.094 & 116.9 & 0.904 & 0.068 \\
\hline 52.77 & 1.733 & 0.089 & 90.31 & 1.086 & 0.070 & & & \\
\hline
\end{tabular}

UV-VIS EXTINCTION
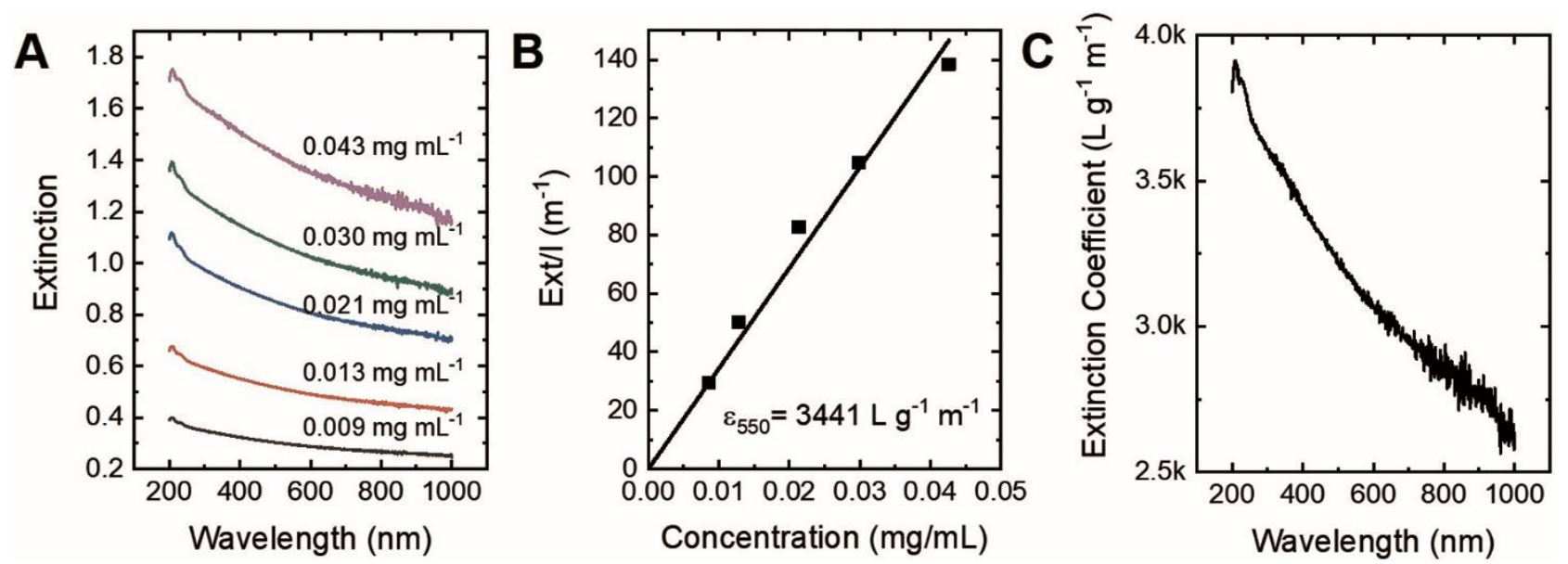

Supporting Figure 14. A) UV-Vis-NIR extinction spectra from 200 to $1000 \mathrm{~nm}$ of $\mathrm{Mo}_{4} \mathrm{VC}_{4}$ flakes in deionized water at concentrations from $\sim 0.01-0.04 \mathrm{mg} / \mathrm{mL}$. B) Linear fit of extinction per path length $(\mathrm{Ext} / \mathrm{l})$ at $550 \mathrm{~nm}$ with respect to concentration using the Beer Lambert equation $(\mathrm{Ext}=\varepsilon \mathrm{Cl})$. C) Extinction coefficient at each wavelength from 200-1000 nm. 


\section{UV-VIS TRANSMISSION}

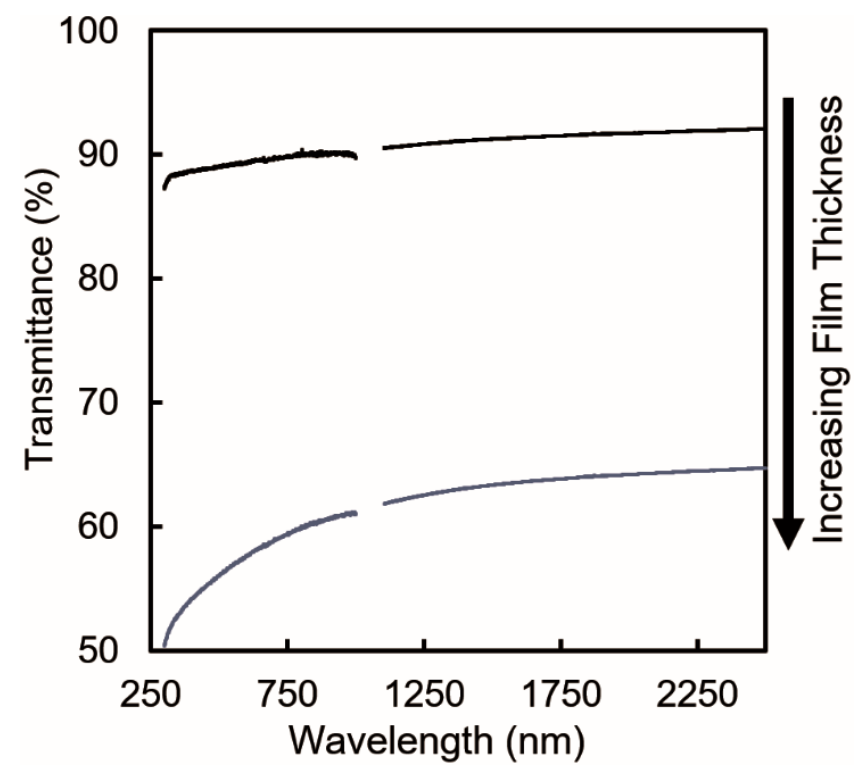

Supporting Figure 15. UV-Vis-NIR transmittance spectra from 300 to $2500 \mathrm{~nm}$ of $\mathrm{Mo}_{4} \mathrm{VC}_{4}$ spray coated onto glass substrates as a function of increasing the spray coating amount. The films have an average surface roughness $\left(R_{\mathrm{a}}\right)$ of approximately $13 \mathrm{~nm}(\mathrm{RMS}=18 \mathrm{~nm}$ ) (black curve) and $26 \mathrm{~nm}$ (RMS=35 nm) (blue curve). 


\section{DFT CALCULATIONS}

Examples of the solid solution structures used for the $\mathrm{Mo}_{4} \mathrm{VAlC}_{4}$ calculations are provided in Supporting Figure 16. The stability tends to increase with a decrease in the volume of the structure. Calculated formation energies and lattice parameters of ordered $\mathrm{M}^{\prime}{ }_{4} \mathrm{M}^{\prime}{ }^{\prime} \mathrm{AlC}_{4} \mathrm{MAX}$ phases are provided in Supporting Table 2.

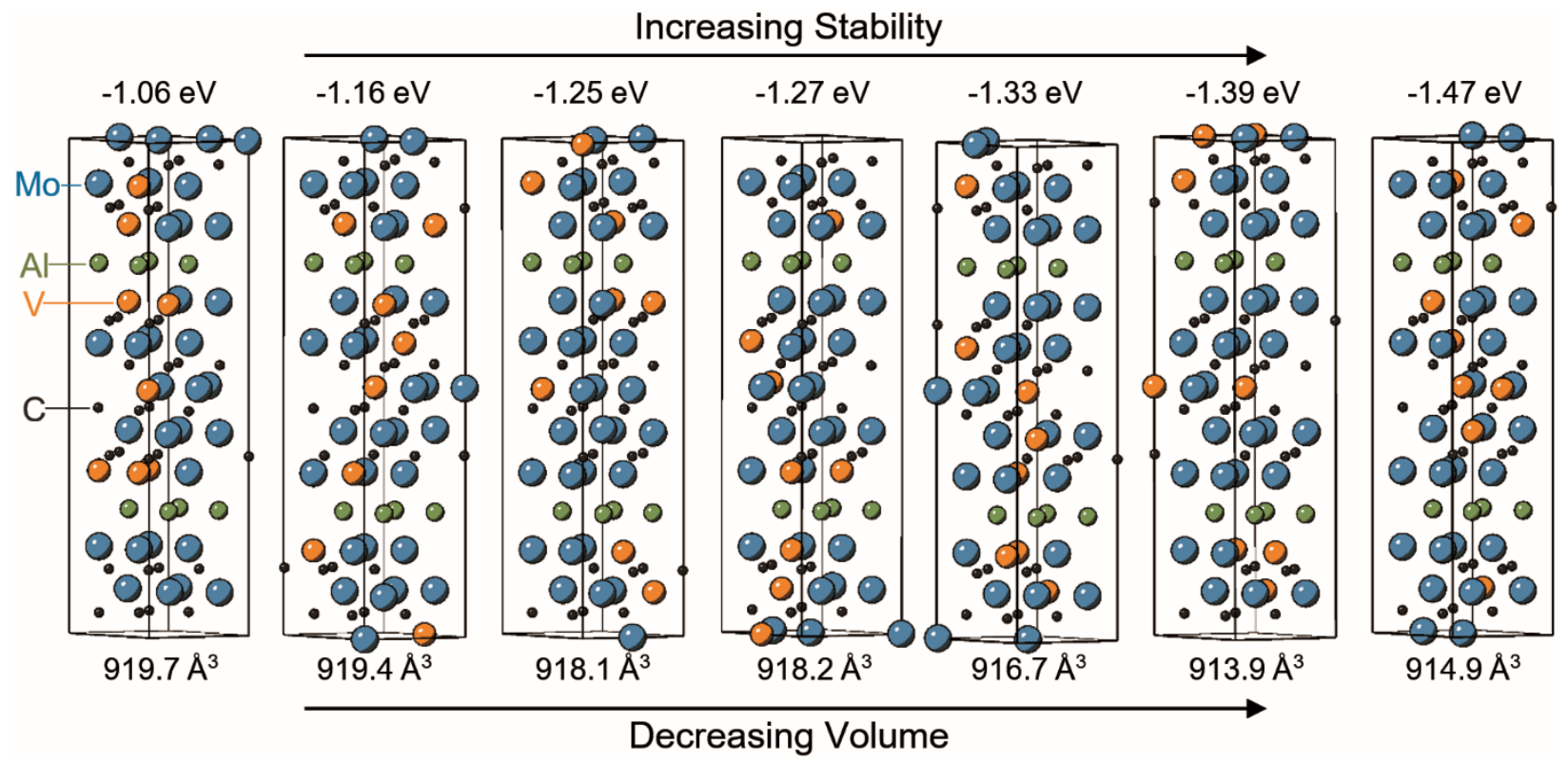

Supporting Figure 16. Seven examples of the solid solution $\mathrm{Mo}_{4} \mathrm{VAIC}_{4}$ structures for which the formation energies were calculated. The formation energies per formula unit and crystal volumes are provided. As the volume of the structure decreases, the stability tends to increase. 
Supporting Table 2. Calculated formation energy (eV/formula unit) and lattice parameters ( $\AA$ ) of ordered $\mathrm{M}_{4}{ }_{4} \mathrm{M}^{\prime \prime} \mathrm{AlC}_{4} \mathrm{MAX}$ phase compositions

\begin{tabular}{|c|c|c|c|c|}
\hline $\mathbf{M}^{\prime}$ & M" $^{\prime \prime}$ & $a$ & $c$ & Eformation \\
\hline $\mathrm{Sc}$ & $\mathrm{Sc}$ & 3.311 & 31.567 & -4.738 \\
\hline $\mathrm{Sc}$ & $\mathrm{Ti}$ & 3.250 & 31.241 & -7.106 \\
\hline $\mathrm{Sc}$ & V & 3.215 & 30.965 & -6.200 \\
\hline $\mathrm{Sc}$ & $\mathrm{Zr}$ & 3.314 & 31.631 & -8.043 \\
\hline $\mathrm{Sc}$ & $\mathrm{Nb}$ & 3.263 & 31.404 & -8.144 \\
\hline Sc & Мо & 3.222 & 31.287 & -6.563 \\
\hline $\mathrm{Sc}$ & $\mathrm{Hf}$ & 3.301 & 31.574 & -8.567 \\
\hline $\mathrm{Sc}$ & $\mathrm{Ta}$ & 3.256 & 31.417 & -9.134 \\
\hline $\mathrm{Sc}$ & $\mathrm{W}$ & 3.216 & 31.322 & -6.944 \\
\hline $\mathrm{Ti}$ & $\mathrm{Ti}$ & 3.087 & 28.518 & -13.552 \\
\hline $\mathrm{Ti}$ & Sc & 3.127 & 29.169 & -11.436 \\
\hline $\mathrm{Ti}$ & V & 3.062 & 28.166 & -12.025 \\
\hline $\mathrm{Ti}$ & $\mathrm{Zr}$ & 3.147 & 28.900 & -13.391 \\
\hline $\mathrm{Ti}$ & $\mathrm{Nb}$ & 3.115 & 28.596 & -12.622 \\
\hline $\mathrm{Ti}$ & Mo & 3.075 & 28.674 & -10.600 \\
\hline $\mathrm{Ti}$ & $\mathrm{Hf}$ & 3.138 & 28.862 & -14.031 \\
\hline $\mathrm{Ti}$ & $\mathrm{Ta}$ & 3.109 & 28.604 & -13.499 \\
\hline $\mathrm{Ti}$ & $\mathrm{W}$ & 3.076 & 28.644 & -10.784 \\
\hline V & V & 2.929 & 27.508 & -7.735 \\
\hline V & Sc & 2.993 & 27.923 & -8.163 \\
\hline V & $\mathrm{Ti}$ & 2.953 & 27.674 & -9.748 \\
\hline V & $\mathrm{Zr}$ & 3.023 & 27.923 & -8.865 \\
\hline V & $\mathrm{Nb}$ & 3.007 & 27.714 & -7.410 \\
\hline V & Mo & 2.947 & 28.008 & -5.681 \\
\hline V & Hf & 3.017 & 27.855 & -9.590 \\
\hline V & $\mathrm{Ta}$ & 3.010 & 27.601 & -8.170 \\
\hline V & W & 2.955 & 27.985 & -5.425 \\
\hline $\mathrm{Zr}$ & $\mathrm{Zr}$ & 3.343 & 30.689 & -15.681 \\
\hline $\mathrm{Zr}$ & Sc & 3.343 & 30.817 & -13.311 \\
\hline $\mathrm{Zr}$ & $\mathrm{Ti}$ & 3.299 & 30.203 & -14.499 \\
\hline $\mathrm{Zr}$ & $\mathrm{V}$ & 3.286 & 29.770 & -12.143 \\
\hline $\mathrm{Zr}$ & $\mathrm{Nb}$ & 3.312 & 30.319 & -14.100 \\
\hline $\mathrm{Zr}$ & Mo & 3.295 & 30.080 & -11.214 \\
\hline $\mathrm{Zr}$ & $\mathrm{Hf}$ & 3.331 & 30.641 & -16.119 \\
\hline $\mathrm{Zr}$ & $\mathrm{Ta}$ & 3.301 & 30.366 & -14.664 \\
\hline $\mathrm{Zr}$ & $\mathrm{W}$ & 3.278 & 30.268 & -11.604 \\
\hline $\mathrm{Nb}$ & $\mathrm{Nb}$ & 3.158 & 29.627 & -8.919 \\
\hline $\mathrm{Nb}$ & $\mathrm{Sc}$ & 3.170 & 29.763 & -10.467 \\
\hline $\mathrm{Nb}$ & $\mathrm{Ti}$ & 3.141 & 29.376 & -10.773 \\
\hline
\end{tabular}




\begin{tabular}{|c|c|c|c|c|}
\hline $\mathrm{Nb}$ & V & 3.116 & 29.209 & -8.069 \\
\hline $\mathrm{Nb}$ & $\mathrm{Zr}$ & 3.202 & 29.654 & -11.390 \\
\hline $\mathrm{Nb}$ & Mo & 3.139 & 29.475 & -6.668 \\
\hline $\mathrm{Nb}$ & $\mathrm{Hf}$ & 3.190 & 29.572 & -11.928 \\
\hline $\mathrm{Nb}$ & $\mathrm{Ta}$ & 3.160 & 29.575 & -9.651 \\
\hline $\mathrm{Nb}$ & W & 3.140 & 29.483 & -6.373 \\
\hline Mo & Mo & 3.081 & 28.628 & 0.419 \\
\hline Mo & $\mathrm{Sc}$ & 3.134 & 28.763 & -3.987 \\
\hline Mo & $\mathrm{Ti}$ & 3.049 & 28.872 & -3.473 \\
\hline Mo & V & 3.000 & 29.038 & -1.328 \\
\hline Mo & $\mathrm{Zr}$ & 3.203 & 28.178 & -3.648 \\
\hline Mo & $\mathrm{Nb}$ & 3.093 & 28.797 & -1.376 \\
\hline Mo & $\mathrm{Hf}$ & 3.192 & 28.182 & -4.117 \\
\hline Mo & $\mathrm{Ta}$ & 3.085 & 28.802 & -1.933 \\
\hline Mo & $\mathrm{W}$ & 3.074 & 28.680 & 1.063 \\
\hline $\mathrm{Hf}$ & $\mathrm{Hf}$ & 3.298 & 30.258 & -17.452 \\
\hline Hf & $\mathrm{Sc}$ & 3.307 & 30.484 & -14.732 \\
\hline $\mathrm{Hf}$ & $\mathrm{Ti}$ & 3.260 & 29.919 & -15.961 \\
\hline $\mathrm{Hf}$ & V & 3.245 & 29.495 & -13.845 \\
\hline $\mathrm{Hf}$ & $\mathrm{Zr}$ & 3.307 & 30.358 & -16.970 \\
\hline $\mathrm{Hf}$ & $\mathrm{Nb}$ & 3.273 & 30.023 & -15.363 \\
\hline $\mathrm{Hf}$ & Mo & 3.255 & 29.801 & -12.780 \\
\hline $\mathrm{Hf}$ & $\mathrm{Ta}$ & 3.263 & 30.071 & -16.141 \\
\hline $\mathrm{Hf}$ & $\mathrm{W}$ & 3.246 & 29.900 & -12.899 \\
\hline $\mathrm{Ta}$ & $\mathrm{Ta}$ & 3.134 & 29.490 & -11.489 \\
\hline $\mathrm{Ta}$ & $\mathrm{Sc}$ & 3.149 & 29.664 & -12.692 \\
\hline $\mathrm{Ta}$ & $\mathrm{Ti}$ & 3.115 & 29.359 & -12.623 \\
\hline $\mathrm{Ta}$ & V & 3.090 & 29.201 & -10.203 \\
\hline $\mathrm{Ta}$ & $\mathrm{Zr}$ & 3.179 & 29.524 & -13.038 \\
\hline $\mathrm{Ta}$ & $\mathrm{Nb}$ & 3.133 & 29.593 & -10.841 \\
\hline $\mathrm{Ta}$ & Mo & 3.120 & 29.369 & -8.577 \\
\hline $\mathrm{Ta}$ & Hf & 3.173 & 29.448 & -13.609 \\
\hline $\mathrm{Ta}$ & W & 3.121 & 29.348 & -8.218 \\
\hline W & W & 3.078 & 28.704 & 3.601 \\
\hline $\mathrm{W}$ & Sc & 3.125 & 28.848 & -2.124 \\
\hline $\mathrm{W}$ & $\mathrm{Ti}$ & 3.058 & 28.817 & -1.420 \\
\hline $\mathrm{W}$ & V & 3.042 & 28.571 & 0.853 \\
\hline $\mathrm{W}$ & $\mathrm{Zr}$ & 3.118 & 29.077 & -1.452 \\
\hline W & $\mathrm{Nb}$ & 3.095 & 28.880 & 0.855 \\
\hline W & Mo & 3.081 & 28.699 & 2.845 \\
\hline W & $\mathrm{Hf}$ & 3.113 & 28.955 & -1.820 \\
\hline W & $\mathrm{Ta}$ & 3.084 & 28.891 & 0.413 \\
\hline
\end{tabular}


Supporting Table 3. Cluster expansion results for both $\mathrm{P} 6_{3} / m m c$ and $\mathrm{P} \overline{6} \mathrm{~m} 2 \mathrm{Mo}_{4} \mathrm{VAlC}_{4}$ crystal structures

\begin{tabular}{|c|c|c|c|c|c|}
\hline ID & Vol/unit cell & $\boldsymbol{a}$ & $\boldsymbol{c}$ & \multicolumn{1}{c|}{ E/unit cell } & E/atom \\
\hline \multicolumn{5}{|c|}{$\mathrm{P} 6_{3} / m m \boldsymbol{c}$} \\
\hline sg194-293 & 228.624 & 3.041 & 28.522 & -188.054 & -9.403 \\
\hline sg194-3417 & 228.557 & 3.036 & 28.557 & -188.051 & -9.403 \\
\hline sg194-767 & 228.636 & 3.041 & 28.534 & -188.029 & -9.402 \\
\hline sg194-2534 & 228.374 & 3.037 & 28.547 & -188.016 & -9.401 \\
\hline sg194-4293 & 228.417 & 3.038 & 28.523 & -188.015 & -9.401 \\
\hline sg194-370 & 228.439 & 3.037 & 28.519 & -187.930 & -9.396 \\
\hline sg194-374 & 228.244 & 3.027 & 28.616 & -187.916 & -9.396 \\
\hline sg194-382 & 228.661 & 3.030 & 28.591 & -187.682 & -9.384 \\
\hline sg194-356 & 230.414 & 3.040 & 28.555 & -187.181 & -9.359 \\
\hline sg194-24 & 230.140 & 3.068 & 28.230 & -186.923 & -9.346 \\
\hline & & & & & \\
\hline sg187-308 & 227.872 & 3.022 & 28.780 & -188.691 & -9.435 \\
\hline sg187-519 & 229.271 & 3.027 & 28.760 & -188.086 & -9.404 \\
\hline sg187-491 & 228.694 & 3.015 & 28.922 & -188.053 & -9.403 \\
\hline sg187-488 & 229.714 & 3.032 & 28.741 & -187.638 & -9.382 \\
\hline sg187-29 & 229.687 & 3.045 & 28.533 & -187.624 & -9.381 \\
\hline
\end{tabular}

